\title{
Drought in the U.S. Caribbean: Impacts on Coastal Estuary Ecosystems
}

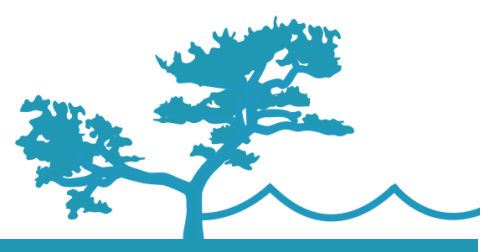

Authors: Brent Murry, USFWS; Miguel Garcia-Bermudez, USFWS; Shelley Crausbay, Conservation Science Partners; Kate Malpeli, National CASC Graphic: Integration \& Application Network, University of Maryland Center for Environmental Science

The topography of Puerto Rico and the U.S. Virgin Islands (USVI) is characterized by steep terrain and short distances to the sea. This means that freshwater runs off the islands quickly, coming into contact with seawater in coastal estuaries. The physical characteristics of estuaries change as the tides rise and fall, creating a wide range of habitats that support diverse plants and wildlife, including economically and culturally important native species such as cetí and land crabs, as well as game fishes such as snook and tarpon. These ecosystems are already heavily threatened by human activities such as urbanization, increased sedimentation, and pollution. Changing climate conditions, such as more frequent and severe drought, pose an additional stressor. Because rivers in Puerto Rico and temporary streams (known locally as "ghuts") in the USVI feed the coastal estuaries of the U.S. Caribbean, changes to streamflow can impact estuaries and the wildlife they support. For example, during prolonged periods of low flow, withdrawals from the Espiritu Santo River, which feeds into the Espiritu Santo estuary in northeast Puerto Rico, can reach $100 \%$ of instream flow and the river can run dry. This reduction in the amount of freshwater entering the estuary can increase salinity levels, altering habitat conditions and leading to declines in the richness and abundance of freshwater species.

\section{About this Series}

This fact sheet is part of a series examining what we know about the impacts of drought on ecosystems and agriculture in the U.S. Caribbean. Explore the other fact sheets on:

- Freshwater Ecosystems

- Tropical Forest Ecosystems

- Crops

- Livestock

View the complete series here: usgs.gov/casc/lslandDrought

\section{Drought can change estuarine landscapes in three ways:}

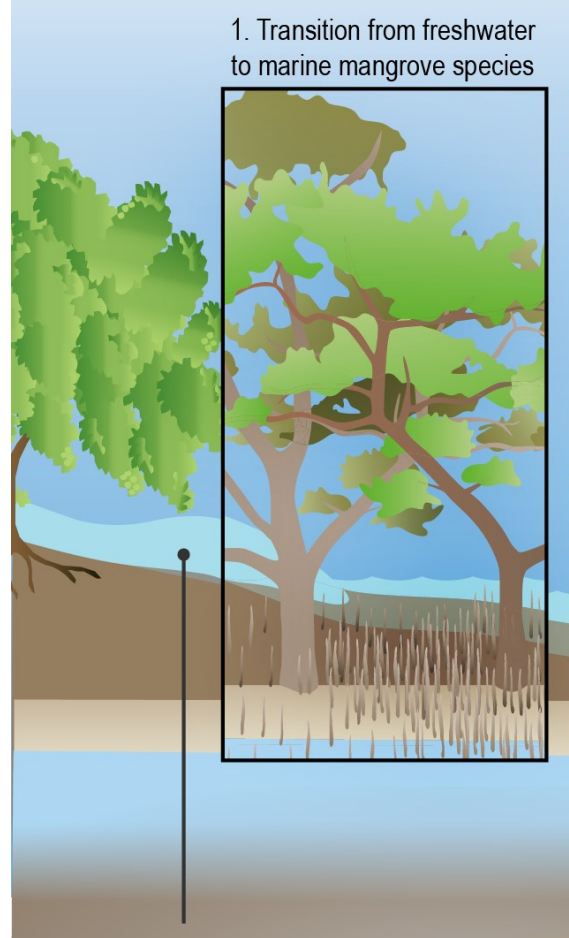

Less freshwater entering estuary due to drier streams, less groundwater, and more human use

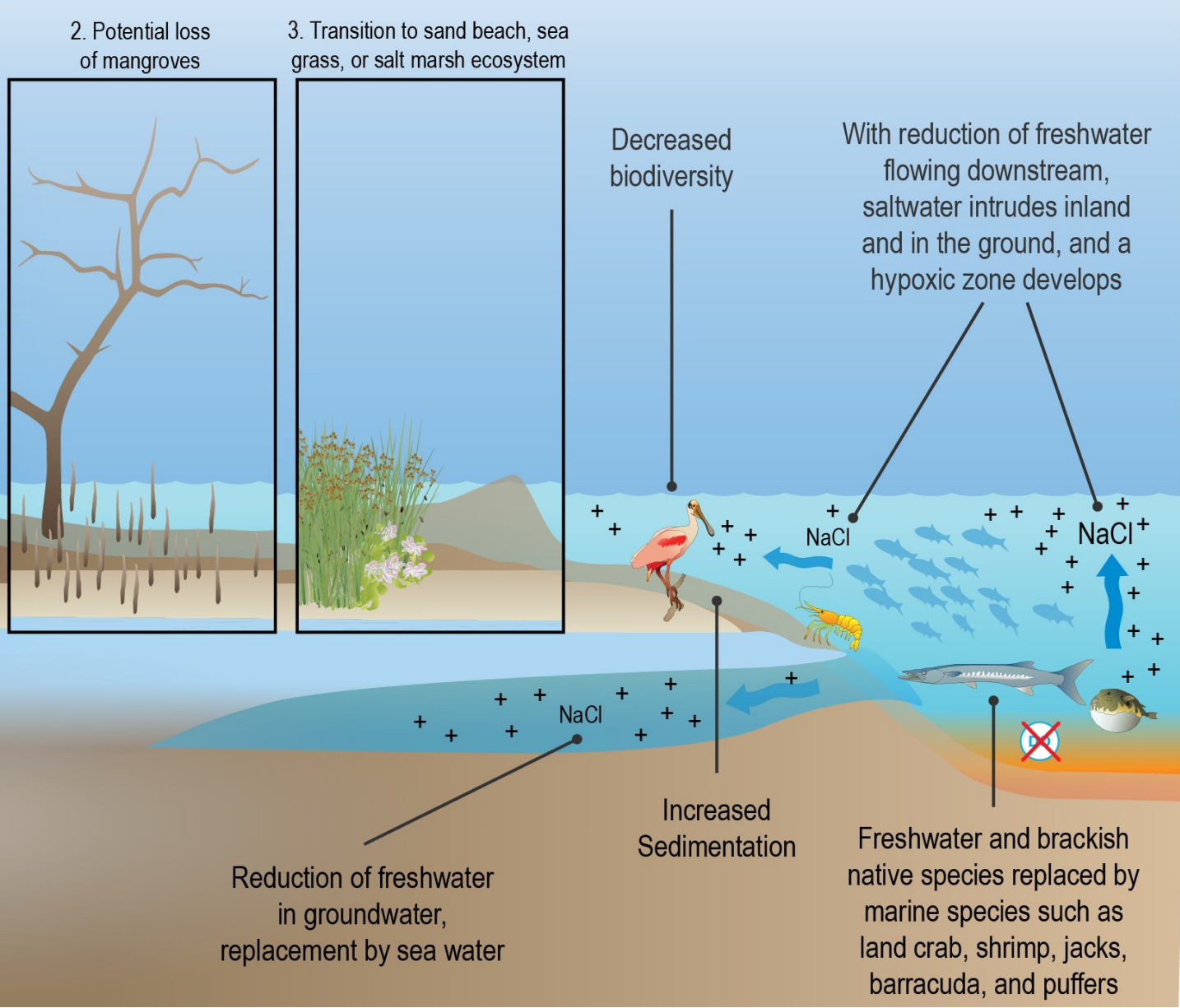


- Wetland Function: Salt-tolerant species will become dominant, changing the ways in which wetlands function. However, it's possible that certain ecosystem services may be preserved. Mangroves are salt tolerant, however the degree of tolerance varies among species. Black mangroves are very sensitive to changes in hydrology, and both drought and flooding can cause mortality.
Habitats: Mangroves could be converted to salt marsh or mud flats, affecting habitat quality for fish and birds.

- Species Assemblages: Freshwater and brackish estuaries support important native species (e.g. cetí and land crabs) and game fish such as snook and tarpon. These systems could change to dominance by marine species such as jacks, barracuda, and puffers.

\section{Spatial Context}

Drought can impact the amount of freshwater that enters estuaries, altering their composition. The amount of saltwater in estuaries is already increasing due to sea-level rise. This saltwater meets freshwater that has its origins in both surface water (e.g. rivers, streams, and overland flows) and groundwater. Decreases in rainfall result in decreased freshwater entering estuaries due to (1) reduced surface flows; (2) reduced aquifer recharge and groundwater flows; and (3) increased human withdrawals, which further drive reductions in surface and groundwater flows. Changes in the distribution and concentration of saltwater can have both shortand long-term impacts on mangroves and other keystone wetlands plant species, with subsequent impacts to the numerous ecosystem services they provide.

\section{Cross-Sector Impacts}

Hotter 21st century drought conditions coincide with a reduction in the amount of freshwater available to coastal estuaries because of an overall negative trend in rainfall and increasing water demand for people. Meanwhile, coastal estuaries are increasingly sensitive to drought because of land use change, fragmented forests, and disconnected rivers that exacerbate drought conditions. Ultimately, drought conditions - including human water use during drought - may lead to broad-scale changes in the plant and animal communities in coastal estuaries that in turn cascade to human communities through altered recreation, fishing, and other ecosystem services.

\section{Future Research Directions}

\section{Key Questions \& Needs}

- How will drought impacts to coastal estuaries differ across Puerto Rico's precipitation gradient?

- Long-term monitoring of estuaries

- Improved understanding of the dynamics between human water use and demand of surface and groundwater interacting with sealevel rise (increasing inshore and underground intrusion of saltwater) and the implications of short- and long-term drought on the salinity gradient and subsequent predictions of wetland habitat changes.

- How does aging infrastructure (e.g. dams in the coastal and lowland areas) influence the fresh- and saltwater balance in coastal and lowland rivers and wetlands?

\section{About Us}

This fact sheet is a product of the 2018 U.S. Caribbean Drought Workshop, hosted by the USDA Caribbean Climate Hub in collaboration with the Climate Adaptation Science Center (CASC) network. View a more detailed description of drought impacts on coastal estuaries at usgs.gov/casc/lslandDrought

CASCs: Delivering science to help fish, wildlife, water, land, and people adapt to a changing climate. Learn more: usgs.gov/casc

Caribbean Climate Hub: Developing and delivering climate adaptation information. Find resources and tools at caribbeanclimatehub.org and climatehubs.oce.usda.gov/hubs/caribbean. International Institute of Tropical Forestry, Río Piedras, Puerto Rico. The USDA is an equal opportunity provider, employer and lender. 